\title{
COMMENTARY
}

\section{The Challenge of Coming to Terms with Evolving Priorities}

\author{
Daniel R. Malcom, PharmD $D^{\mathrm{a}, \mathrm{b}}$ \\ ${ }^{a}$ Sullivan University, College of Pharmacy and Health Sciences, Louisville, Kentucky \\ ${ }^{\mathrm{b}}$ Associate Editor, American Journal of Pharmaceutical Education, Arlington, Virginia
}

Corresponding Author: Daniel R. Malcom, Sullivan University, College of Pharmacy and Health Sciences, 2100 Gardiner Ln, Louisville, KY 40205. Tel: 502-413-8969. Email: dmalcom@sullivan.edu

Submitted March 29, 2021; accepted March 31, 2021; ePublished April 2021

Keywords: growth, development, faculty development

Among the many lessons and ongoing challenges of the COVID-19 pandemic has been its effect on the relationship between our home and work lives. The ideas of "work-life balance" or "work-life blend," both of which were popular topics in the years leading up to 2020, entered an entirely new and uncharted level of complexity when the personal and professional worlds for many collided suddenly and without adequate warning or preparation. ${ }^{1,2}$ In many cases, years of careful planning or concerted effort to separate or otherwise partition work and home from one another evaporated and the multitude of challenges inherent in complete integration of work and home became readily apparent.

Despite the numerous negative aspects of the pandemic, one potential silver lining (if it can be called that) is that many communities of individuals who may have been traditionally living disparate existences focused on their own goals, priorities, and problems were suddenly faced with a communal, nearly existential challenge. Communal challenges can foster a shared sense of ownership and activate many positive attributes in individuals that can lead to greater individual and group well-being. ${ }^{3}$ At an individual level, however, and separate from the direct physical or health-related complications of the pandemic, the communal challenge of COVID-19 served as a massive disruption to our own plans and goals for our lives and careers that had and have both immediate and perhaps more sustained and long-term consequences. Whether that meant a long-planned vacation had to be canceled or even a dossier submission for promotion or tenure was put on hold, the pandemic inserted itself as an uncontrollable and uncertain external roadblock to both individual and collective goalsetting and achievement.

As department chair, my ongoing regular conversations with faculty members stretch the full spectrum of events, emotions, and situations running through their personal and professional lives. As might be expected given the circumstances of this year, many of the more serious conversations with faculty members have been focused on the intersection of the expectations and goals they had for themselves with the realities of the world around them and the resulting emotional impact. I have found that many faculty members have felt a profound sense of personal and professional disappointment with themselves for having not made what they believed to be adequate progress toward their goals over the past year. The emotion of "disappointment" has been characterized as stemming from unmet expectations, just as pride and accomplishment derives from meeting or exceeding expectations. ${ }^{4}$ As a normal part of life and work, there are regular formal and informal points in time that serve as progress markers both personally and professionally. Some are compulsory, such as a $30^{\text {th }}, 40^{\text {th }}$, or $50^{\text {th }}$ birthday, while others are levied by others or by our employers (eg, annual evaluation). What ties these moments together is that they each set us up to feel a sense of pride in what we have achieved or disappointment in our lack of progress. Put another way, these moments that allow reflection and evaluation of our relative progress toward our pre-specified goals also can essentially force us to feel either a sense of relative accomplishment or one of disappointment. In that way, our perspective and self-perception of both ourselves and our place in life and in the world can be keys to the resulting emotion and how it affects us.

In this discussion, I am reminded of experiences in my own life and how my perspective was unknowingly affected by circumstances in the wider world. For most of my early life, I dreamed of becoming a nationally known broadcast journalist and anchoring the network evening news like my heroes Tom Brokaw, Peter Jennings, and Dan Rather. As early as elementary and middle school, I regularly set up a bulky home VHS video camera to make my own "studio" and film myself delivering the news with hand-drawn logos and homemade graphics based off of those I saw on our local television news stations. I even brought in family members in to be "interviewed" on my broadcasts about local or national events. As 
I grew older, I made decisions about which classes and extracurricular activities to pursue based on this goal, joining the high school newspaper staff and advancing from reporter to features editor eventually to assistant editor.

As time passed and college approached, circumstances in life changed and my priorities shifted. The terrorist attacks of September 11, 2001 occurred my senior year of high school just as I was readying my applications to various colleges and my on-site campus visits to programs in New York City, NY and Washington, DC. I am unable to retrospectively pinpoint the exact moment, but at some point, the goal of becoming a broadcast journalist that I had been building toward for so long became less important and my thoughts and plans moved to different concerns about finding a fulfilling career and ensuring financial stability amidst the new world that emerged after 9/11. Eventually, I found pharmacy as a career. In retrospect, however, it is difficult now to reconcile my younger self with the one I became after that shift. Up to that point in life, I had a very clear dream to become a broadcast journalist with specific goals and a detailed, stepwise plan to accomplish that goal. The philosophical question that emerges, then, is why am I not living in a state of disappointment with myself for not achieving those goals and fulfilling that dream? How could I have abandoned nearly 10 years of dreams within just a few months prior to college? Objectively, it would be understandable if I felt disappointment (either prominent or subtle internally); however, though I certainly feel disappointment about other aspects of life and am no stranger to that emotion, I do not feel that I missed out on my lifelong dream and feel fulfilled in my chosen career path of pharmacy education and leadership.

The COVID-19 pandemic has been compared to the terrorist attacks of $9 / 11$ in the US in many facets, including the collective grief and trauma felt by people across demographic groups and locations. ${ }^{5}$ Most relevant for this discussion, goals and plans (both personal and professional) were disrupted for many Americans and others from around the world. In the acute time period after the 9/11 terrorist attacks, the disruptions were tangible and prominent, such as the complete grounding of US commercial air travel and the shock to the US financial system after entire companies based in the World Trade Centers in New York City were no more. As time passed, however, the disruptions became less prominent (or we simply got used to them) and a type of "new normal" emerged, resetting the equilibrium and forever codifying "pre-9/11" and "post-9/11" as common terms to distinguish periods of time.

Systematically reevaluating our priorities based on new and evolving events and circumstances in our lives is a natural part of growth and development, yet that nagging feeling of disappointment can remain present despite our everpresent positive self-talk and even external objective sources (such as our direct supervisors or family members) reassuring us that we are making the right decisions. Deep in the middle of a crisis, it can be difficult to evaluate our perspective and understand that our goals are never static objects that are unmovable and immune to the whims and effects of intervening circumstances. Recently, I was reminded of the effect of circumstances on my own goals in a much more small-scale but tangible way when I noticed a flat tire on my vehicle when attempting to drive into work. All of the goals, hopes, and ambitions I had for the day seemingly evaporated in an instant as I realized that the flat tire would have to be addressed right away for any of the other tasks to be accomplished. Later in the day, as I paid the mechanic and picked my vehicle up from the auto shop, I noticed I did not feel a sense of disappointment in my lack of accomplishing the goals I set out for the day, but rather a small sense of pride in having successfully dealt with and overcome this unexpected challenge with time left in the day to spare. This "micro experience" was representative for me of the powerful effect that resetting or reevaluating expectations can have on overall emotional well-being, a sentiment supported by others in leadership in academia and beyond. ${ }^{6,7}$

We must take a collective pause and resist the temptation to judge and overly criticize ourselves for failing to meet goals we set in a "pre-pandemic" world. ${ }^{8}$ A helpful question relevant to this discussion could be asking yourself if the "you" at 14,16 , or 18 years of age would feel a sense of pride or one of disappointment in the individual that you have become and what you have accomplished? I believe it is unlikely that our younger selves would see what we have managed to achieve with anything other than pride. The world around us has changed and is continuing to evolve to meet the challenges we face, and it is critical to view the act of goal setting itself, and the systematic evaluation of progress toward those goals through the lens of circumstances.

\section{REFERENCES}

1. Halley MC, Mathews KS, Diamond LC, et al. The intersection of work and home challenges faced by physician mothers during the Coronavirus Disease 2019 Pandemic: a mixed-methods analysis. J Womens Health (Larchmt). 2021 Mar 23. doi: 10.1089/jwh.2020.8964. Epub ahead of print.

2. Aczel B, Kovacs M, van der Lippe T, Szaszi B. Researchers working from home: benefits and challenges. PLoS One. 2021;16(3):e0249127. doi: 10.1371/journal.pone.0249127.

3. Hobfoll SE, Schröder KE, Wells M, Malek M. Communal versus individualistic construction of sense of mastery in facing life challenges. J Soc Clin Psychol. 2002;21(4):362-99. doi: 10.1521/jscp.21.4.362.22596. 
4. Johnson JA. The Psychology of Expectations. Psychology Today. February 17, 2018. https://www.psychologytoday.com/us/blog/cui-bono/201802/the-psychology-expectations. Accessed March 29, 2021.

5. Kuntz JC. Resilience in times of global pandemic: Steering recovery and thriving trajectories. Appl Psychol. 2020 Nov 23:10.1111/apps.12296. doi: 10.1111/apps.12296.

6. Imperiale MJ. Pandemics and People. mSphere. 2020;5(3):e00410-20. doi: 10.1128/mSphere.00410-20.

7. de Jong EM, Ziegler N, Schippers MC. From Shattered Goals to Meaning in Life: Life Crafting in Times of the COVID-19 Pandemic. Front Psychol. 2020;11:577708. doi: 10.3389/fpsyg.2020.577708.

8. Clark D, Carl P. How to Reset Your Goals During a Crisis. Harvard Bus Rev. June 15, 2020. https://hbr.org/2020/06/how-to-reset-your-goals-during-a-crisis. Accessed March 29, 2021. 